\title{
The Salt Fluxes in a Tidally-Energetic Estuary
}

\author{
J. H. Simpson ${ }^{a}$, R. Vennell ${ }^{b}$ and A. J. Souza ${ }^{c}$ \\ ${ }^{a}$ University of Wales, Bangor, School of Ocean Sciences, Menai Bridge, Anglesey LL59 5EY, U.K. \\ ${ }^{b}$ Department of Marine Science, University of Otago, Dunedin, New Zealand \\ ${ }^{c}$ Proudman Oceanographic Laboratory, Bidston Observatory, Bidston CH43 7RA, U.K.
}

Received 10 February 2000 and accepted in revised form 8 May 2000

\begin{abstract}
Time series measurements of velocity and salinity have been used to examine the salt flux components in the tidally-energetic regime of the Conwy Estuary in North Wales. The instantaneous volume transport, up to $400 \mathrm{~m}^{3} \mathrm{~s}-1$, was deduced from a current meter located in mid-channel using a frictional model with a correction for the observed mean velocity shear. Transport estimates obtained in this way have been compared with independent measurements of integrated cross-section transport using a boat-mounted ADCP. The two determinations of the flow are found to be in satisfactory agreement confirming the validity of the frictional model. Estimates of the covariance of the tidally varying transport $Q_{t}$ and salinity $S_{t}$ indicate that a consistently upstream transport of salt occurred over the 9 day period of the observations. This upstream tidal pumping flux $\left(\approx 60 \mathrm{~kg} \mathrm{~s}^{-1}\right)$ was greater than the downstream transport $(\approx 27 \mathrm{~kg} \mathrm{~s}-1)$ estimated from the freshwater river discharge $Q_{f}\left(\approx 3 \mathrm{~m}^{3} \mathrm{~s}^{-1}\right)$. The difference in the salt fluxes implies a net upstream movement of salt and was consistent in sign with the observed general increase in mean salinity which occurred in the upper estuary prior to a rapid salinity decrease due to a large increase in freshwater discharge at the end of the measurement period. The observations have been interpreted to illustrate the problems involved in trying to determine the net flux of a dissolved constituent from such as estuary. Using estimates of the net inflow from river gauging to determine the volume discharge $Q_{0}$, estimates of the net flux are realistic but, in the absence of river gauging, large errors are likely to arise from the uncertainties in $Q_{0}$, which is the small difference between large flood and ebb transports.
\end{abstract}

(C) 2001 Academic Press

Keywords: estuaries; fluxes; salt balance; tidal pumping; Conwy Estuary

\section{Introduction}

Efforts to understand and quantify the interactions across the land-ocean boundary have led to an increasing focus on the fluxes of biogeochemically active components through estuarine systems. Estuaries are the most significant, although not the only, route through which terriginous material enters the ocean. This concentration of land ocean fluxes in estuaries apparently offers the prospect of estimating net transport to the ocean from long sections of the land ocean boundary with a relatively limited set of measurements in the principal estuary systems. The determination of net fluxes in estuaries is, however, complicated by tidal motions which require observations to be extensive in time, in order to allow averaging over tidal cycles, and of sufficient spatial resolution to permit accurate integration across the estuary section in tidal flows which may exhibit considerable horizontal and vertical structure. In calculating the net flux of any property we are inevitably taking the small difference between two large numbers associated with the ebb and flood flows and substantial errors may result (e.g. Lane et al., 1997).
These problems are particularly acute in estuaries where the oscillatory tidal flux is large compared with the mean flow and where the latter may not be properly known from river gauging of the freshwater input. In an effort to resolve net fluxes in a tidally energetic estuary in Malaysia (Simpson et al., 1997), we have proposed the use of the salt balance as a constraint on the system which can be used to estimate the mean freshwater input from a number of ungauged sources. Estimates of the net flux of, for example nutrients, may then be obtained by combining the mean flow flux with the diffusive flux.

In order to test this approach and evaluate the accuracy with which we might hope to determine net fluxes, we have analysed a series of measurements from the Conwy Estuary of North Wales. In reporting the results in this paper we attempt to answer two basic questions about fluxes. The first is whether we can establish the salt balance in a tidally energetic estuary in a situation where the river discharge is adequately gauged. The second question is to what extent we might hope to estimate the net fluxes of water constituents to the ocean in such estuaries. 


\section{J. H. Simpson et al.}

To set the context of our new measurements and analysis we shall briefly review the understanding of fluxes and the nature of the salt balance in tidally energetic estuaries. We next proceed to describe the observations in the Conwy before presenting the time series of flow, salinity and temperature and the analysis of transport and salt flux. We then consider the problem of estimating the seaward flux of freshwater as a surrogate for any land-derived constituent before the concluding discussion.

\section{Fluxes and the salt balance in estuaries}

Much of our understanding of the circulation and mixing processes in estuaries is represented in the classical papers of Hansen and Rattray $(1965,1966)$ who used an idealized solution for the density driven circulation to estimate its contribution to the upstream flux of salt. The total upstream flux is a combination of the density-driven flux $\left(\mathbf{S}_{\mathbf{3}}\right)$ with a second upstream flux contribution arising from covariance of the tidal transport and tidally varying salinity $\left(\mathbf{S}_{2}\right)$, the so-called 'tidal pumping' or 'tidal diffusion' term. Together these fluxes are considered to oppose the downstream transport of salt associated with the net flow $\left(\mathbf{S}_{1}\right)$ so that, in the case of steady state balance, we must have: $\mathbf{S}_{1}+\mathbf{S}_{2}+\mathbf{S}_{3}=0$

The ratio of the tidal diffusion term to the total upstream flux $v=\mathbf{S}_{\mathbf{2}} /\left(\mathbf{S}_{\mathbf{2}}+\mathbf{S}_{\mathbf{3}}\right)$ is a key estuarine parameter which is central to the Hansen-Rattray (1966) classification scheme for estuaries in which measures of mean stratification and circulation are used to identify the value of $v$ for a particular estuary and hence the dominant mode of upstream salt transport. While the basis of the Hansen Rattray model is widely accepted as a conceptual picture of the principal processes involved in estuarine salt transport, there have been rather few attempts to directly determine the individual contributions to the salt flux and demonstrate that they lead to long term balance in an estuary. In particular, little is known of the tidal diffusion term $\mathbf{S}_{2}$ and the irreversible processes in the tidal cycle which bring about a net transport of salt and other water constituents.

In computing fluxes for a tidally energetic estuary like the Conwy, in which vertical mixing is almost complete and tidal diffusion is dominant $(v=>1)$, we can simplify the general expansion problem (see Hansen, 1965; Dyer, 1997) by considering only the transverse variation in the flow and the concentration of the scalar property. So, for example, the salinity $s$ and the axial flow per unit width $q$ are written as

$$
\begin{gathered}
s(y, t)=\langle\bar{s}\rangle+s_{1}(y)+\left\langle s_{t}\right\rangle+s_{2}(y, t) \\
q(y, t)=\langle\bar{q}\rangle+q_{1}(y)+\left\langle q_{t}\right\rangle+q_{2}(y, t)
\end{gathered}
$$

where $\langle>$ denotes the section mean and an overbar represents a time mean over one or more tidal cycles. The first term on the right-hand side of these expressions, therefore, represents the time averaged section mean while $s_{1}$ and $q_{1}$ represent deviations from $\langle\bar{s}\rangle$ and $\langle\bar{q}\rangle$. The tidal variations are denoted by $s_{t}(\mathrm{y})$ and $q_{t}(\mathrm{y})$ which have section means $\left\langle s_{t}\right\rangle$ and $\left\langle q_{t}\right\rangle$. The terms $s_{2}$ and $q_{2}$ are the deviations from the section mean and, at any stage of the tide, will average to zero when summed over the section.

The total flux of water is then

$$
\begin{aligned}
Q & =\int_{0}^{b} q d y=\int_{0}^{b}\left(\langle\bar{q}\rangle+\left\langle q_{t}\right\rangle\right) d y \\
& =b\left(\langle\bar{q}\rangle+\left\langle q_{t}\right\rangle\right)=Q_{0}+Q_{t}
\end{aligned}
$$

where $Q_{0}$ and $Q_{t}$ represent the total residual and tidal flows across the section. Similarly for the time-averaged salt flux $\left(\mathrm{kg} \mathrm{s}^{-1}\right)$, we have:

$$
\begin{aligned}
S=\rho \int_{0}^{b} \overline{(q s)} d y= & \rho b\left(\langle\bar{q}\rangle\langle\bar{s}\rangle+\left\langle q_{1} s_{1}\right\rangle\right. \\
& \left.+\overline{\left\langle q_{t}\right\rangle\left\langle s_{t}\right\rangle}+\overline{\left\langle q_{2} s_{2}\right\rangle}\right) \\
& \approx \rho\left(Q_{0} S_{0}+\overline{Q_{t} S_{t}}\right)
\end{aligned}
$$

where $\left.Q_{0}=b\langle\bar{q}\rangle, Q_{t}=b\left\langle q_{t}\right\rangle, S_{0}=\bar{s}\right\rangle$ and $S_{t}=\left\langle s_{t}\right\rangle$. In the approximation of the last line we are assuming that the terms depending on the sectional deviations $s_{1}$ and $s_{2}$ are small in relation to the leading terms. When there has been no net change of salt in the estuary, so that $\mathrm{S} \approx 0$, the requirement of salt balance allows us, in principle, to determine $\left.Q_{0}=\bar{q}\right\rangle$ from the covariance of $Q_{t}$ and $S_{t}$ as proposed in Simpson et al. (1997). Equation 3 applies equally to other scalar properties and indicates the requirement for tidal cycle measurements of concentrations.

\section{The Conwy Estuary}

The Conwy Estuary of North Wales (Figure 1) extends $22 \mathrm{~km}$ from its tidal limit at Llanrwst down to its mouth just north of Deganwy where it opens into the Irish Sea. The estuary system is forced at the mouth by strong tides with a springs range of $6 \mathrm{~m}$ and at its landward limit by freshwater input which varies in the range $0 \cdot 5-500 \mathrm{~m}^{3} \mathrm{~s}^{-1}$ with a mean close to $20 \mathrm{~m}^{3} \mathrm{~s}^{-1}$. Approximately $67 \%$ of the freshwater inflow is gauged at the Environment Agency monitoring station at Cwm Llanerch $(\approx 4 \mathrm{~km}$ upstream from 


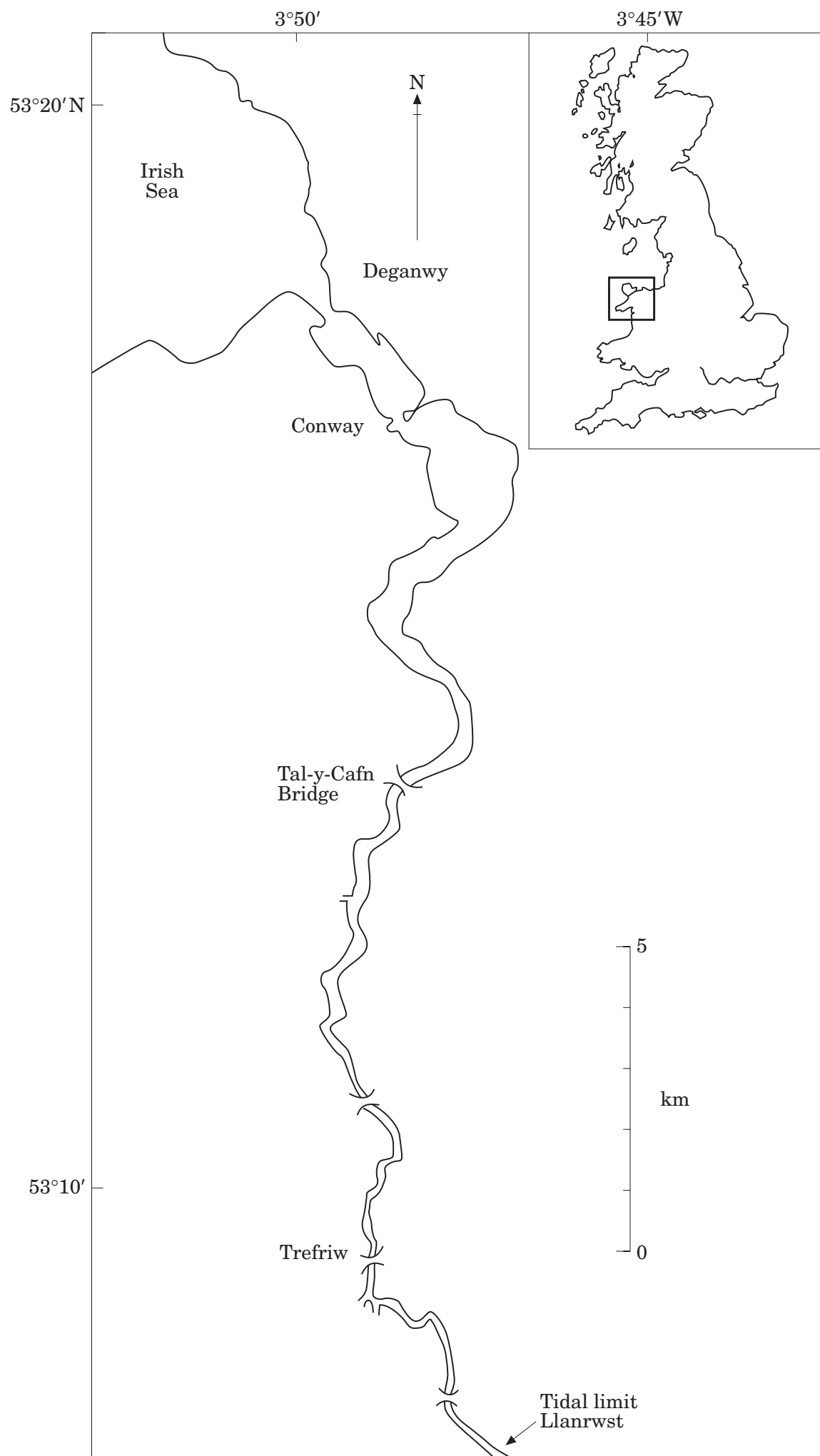

Figure 1. Location and plan of the Conwy Estuary of North Wales. The estuary extends from its mouth at Deganwy to the limit of tidal influence which occurs at the town of Llanrwst. Measurements were made from instruments attached to the road bridge at Tal-y-Cafn. 


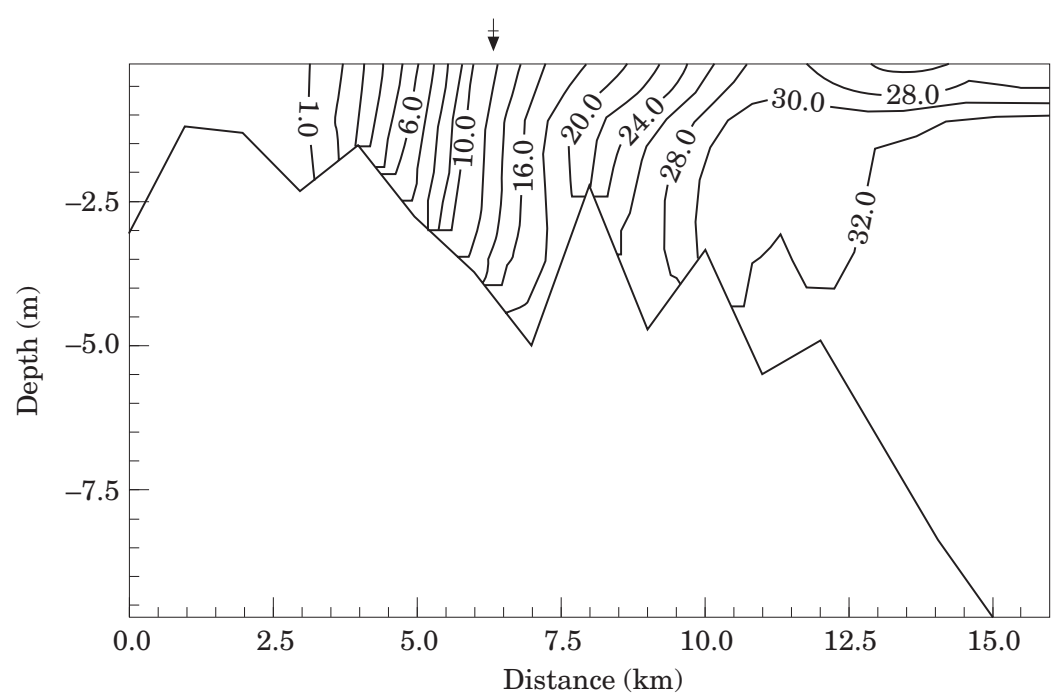

FIGURE 2. Longitudinal section of salinity near highwater from a rapid profile of measurements made from a survey vessel moving downstream between 1507 and 1622 BST on 16/7/98. (Conwy highwater 1550 BST.) The arrow symbol denotes the position of the main observation site at Tal-y-Cafn Bridge.

Llanrwst). The ratio of tidal range to mean depth in the estuary is such that much of the estuary is effectively evacuated each tidal cycle by the large tidal volume exchange which exceeds the mean river input by a factor of $\approx 20$.

The large tidal currents involved in this exchange ensure that most parts of the estuary are well mixed for most of the tidal cycle. An axial section of the salinity distribution along the estuary (Figure 2) close to the time of high water shows the isohalines to be close to vertical along the estuary except near the mouth where some stratification is evident. There is a region of strong salinity gradients apparent in the central section of the estuary which is reformed each tide as high salinity seawater enters the estuary on the rising tide to confront new freshwater moving downstream. The axial gradients are even stronger on the flood and, as shown in Turrell et al. (1996), decrease rapidly until, by the middle of the ebb flow, the maximum gradients are reduced by factor of $\sim 2$ relative to the flood value. The intense axial gradients during the flood interacts with the tidal flow to produce transverse gradients which induce a significant transverse circulation (Nunes \& Simpson, 1985).

In the central section of the estuary, above and below Tal-y-Cafn Bridge (Figure 1), the structure is close to complete vertical homogeneity throughout the tidal cycle as can be seen in Figure 3. This plot also illustrates the rapid time-dependent changes in the salinity in this section of the estuary and the marked asymmetry between flood and ebb in the tidal elevation which is a further consequence of the large ratio of tidal elevation to mean depth.

\section{Instruments and observational strategy}

The principal data set to be considered consists of a continuous nine day time series of velocity, surface elevation, salinity and temperature which we have obtained from an instrument deployment at Tal-yCafn Bridge (Figure 1). Two Aanderaa current meters, recording salinity and temperature as well as current speed and direction, were located at heights of $1 \mathrm{~m}$ and $3 \mathrm{~m}$ above the bottom in mid channel; the lower instrument was immersed throughout the tidal cycle while the upper current meter was located at approximately mid-depth at highwater. The instruments were attached to a taut wire stretched between the bridge structure and a weight on the estuary bed. A tide gauge was also deployed on the estuary bed near mid channel. The arrangement of instruments on the bridge section is shown in Figure 4 along with the cross estuary depth profile which was determined by an echo sounder survey. Both current meters and the tide gauge were set to record at 5 min intervals.

\section{Time series of flow and salinity}

The data sets obtained from the deployment in February 1996 are summarized in the presentation of Figure 5 which shows time series of the velocity, salinity and temperature recorded by the lower current meter and the surface elevation over a nine day period. Data return was complete over this period but the current meters failed on day 40 when their rotors were blocked by a flood which brought large quantities of flotsam down the river. The velocity 


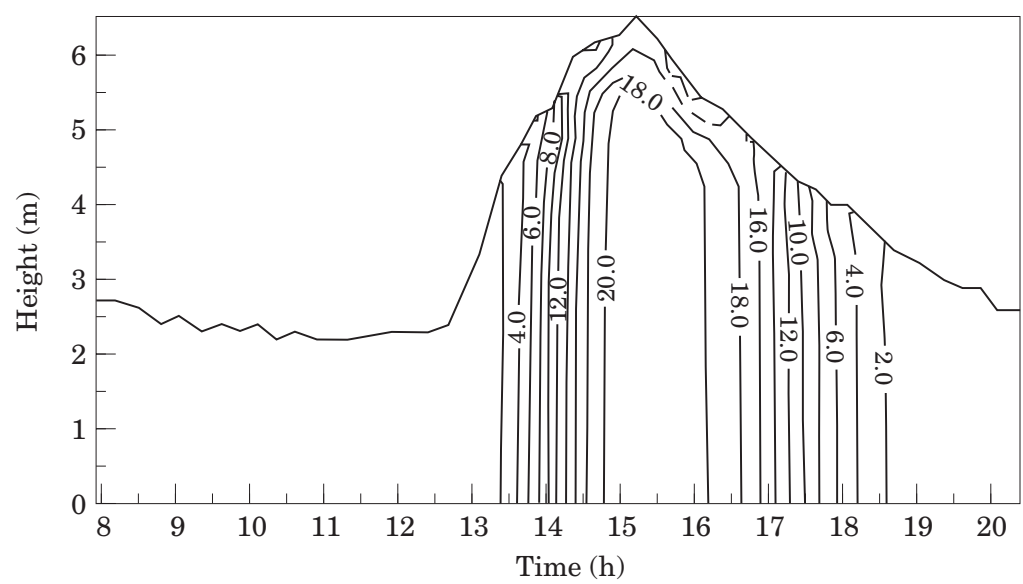

FIGURE 3. Salinity cycle in mid-channel $250 \mathrm{~m}$ north-east of Tal-y-Cafn Bridge 14 July 1998. Times in BST.

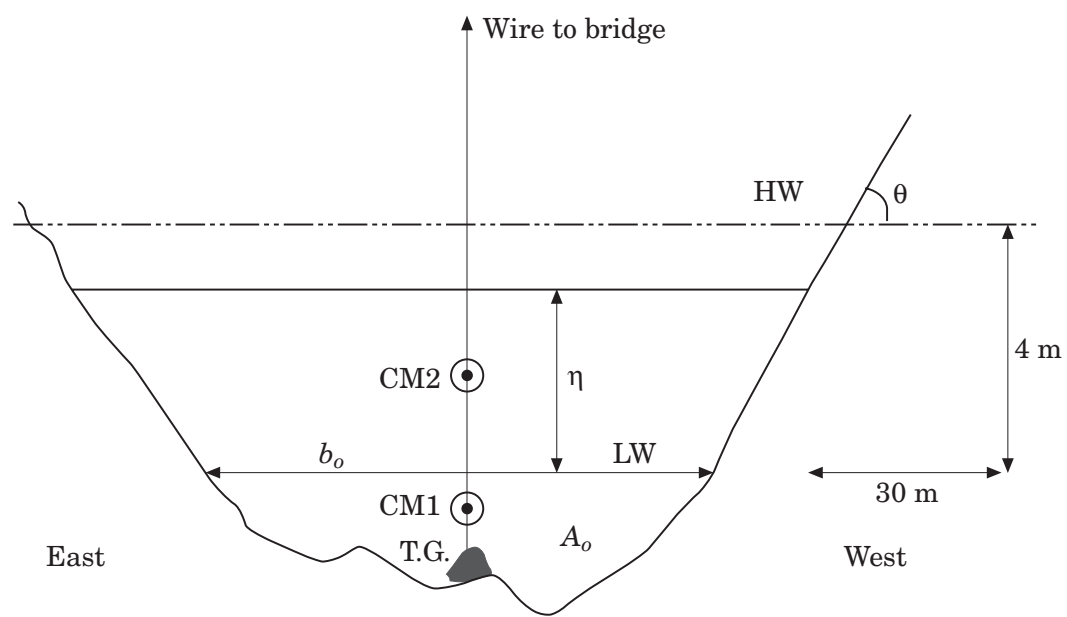

Figure 4. Channel section of the estuary at Tal-y-Cafn Bridge showing positions of the current meters (CM1 and CM2) and the tide gauge (T.G.). Cross-section bathymetry is based on an echo-sounder survey on 9 February 1996. Also shown are the parameters used in determining the cross-sectional area A from a trapezoidal approximation. $\eta$ is the surface elevation measured from a LW datum where the estuary width is $b_{0}$. The area of the cross-section below the datum is $A_{0}$ while the angle $\Theta$ represents the slope of the sea-bed at the shoreline.

shown is the flow along the axis, i.e. the current vector resolved along the local axis direction $\left(054^{\circ} \mathrm{T}\right)$.

During the period of observation the tidal range increase from just after neaps (day 30) to springs (day 37). Maximum salinities increased from just over 15 to $\approx 27$ at springs and remained at this level until the onset of the flood on day 41 . There was little vertical structure in salinity. During periods when both instruments were immersed, the differences in their salinity records rarely exceeded 2 and were typically less than 1 .

In a time-expanded plot of three tidal cycles [Figure 5(c)] the marked asymmetry of the tidal flow in the Conwy is apparent. The flood flow is of short duration $(3.0 \mathrm{~h})$ with maximum flow speeds of $\approx 100 \mathrm{~cm} \mathrm{~s}^{-1}$ while the ebb lasts for $9 \cdot 4 \mathrm{~h}$ with speeds up to $55 \mathrm{~cm} \mathrm{~s}^{-1}$. The velocity shear is also asymmetric as can be seen from the parallel plot of the currents from the two instruments for the periods when the upper instrument is immersed. During the flood the velocities recorded at the two levels $(1 \mathrm{~m}$ and $3 \mathrm{~m}$ above the bed) are closely similar while on the ebb there is a systematic difference of up to $25 \mathrm{~cm} \mathrm{~s}^{-1}$ between the two instruments. Allowance for this shear component will need to be incorporated in our estimates of the total flow based on a frictional model to which we now turn.

\section{Estimating the transport $\mathbf{Q}$}

In order to extrapolate from continuous measurements of flow at a single point to an estimate of the 
136 J. H. Simpson et al.
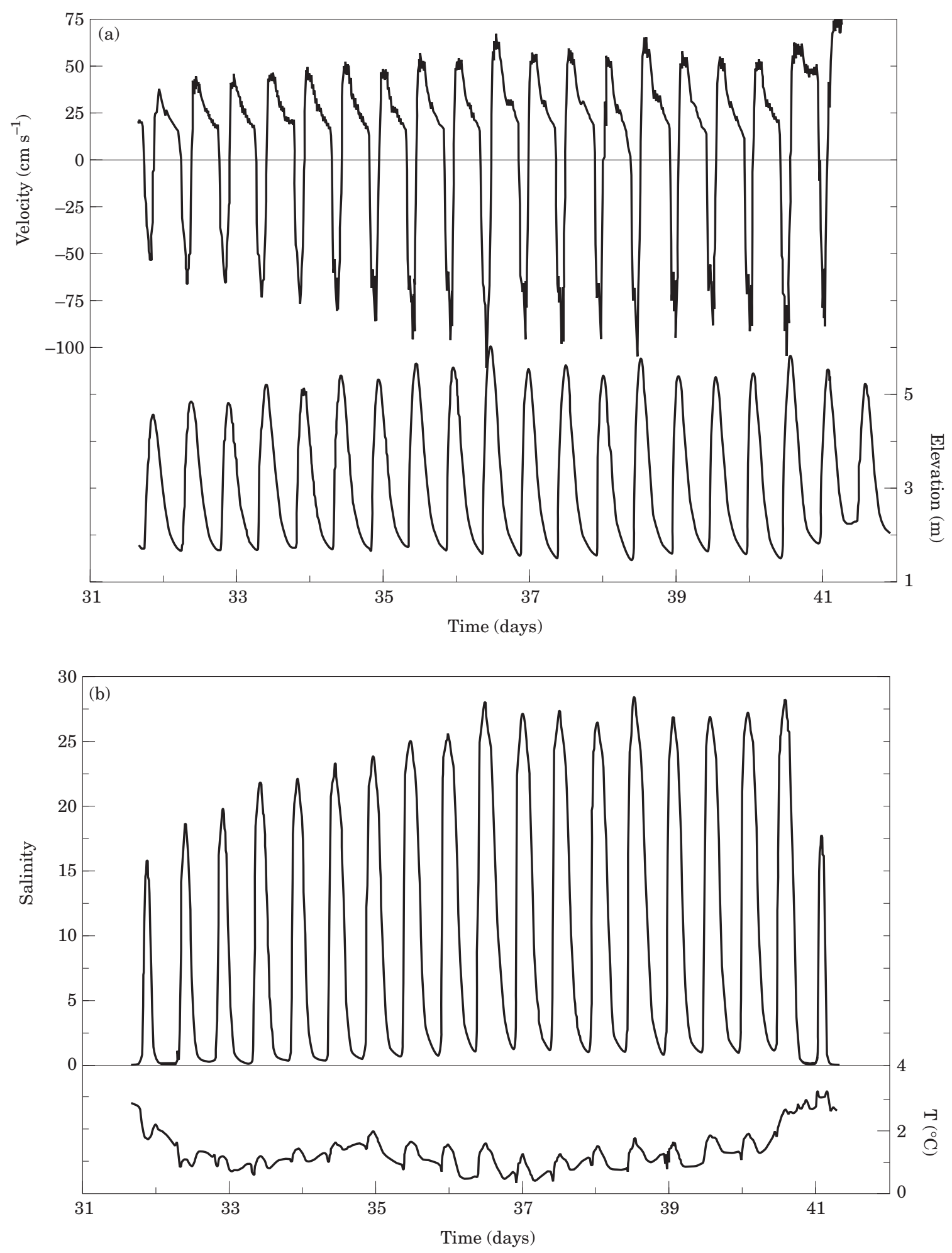

Figure 5. ( $a$ and $b$ ).

total transport we employ a simple frictional balance as suggested by Smith (1980). It is assumed that, at each point across the estuary section, there is a balance between the longitudinal pressure gradient $(P G)$ and the bottom frictional stress $\tau$ which may be expressed in terms of the local frictional velocity 


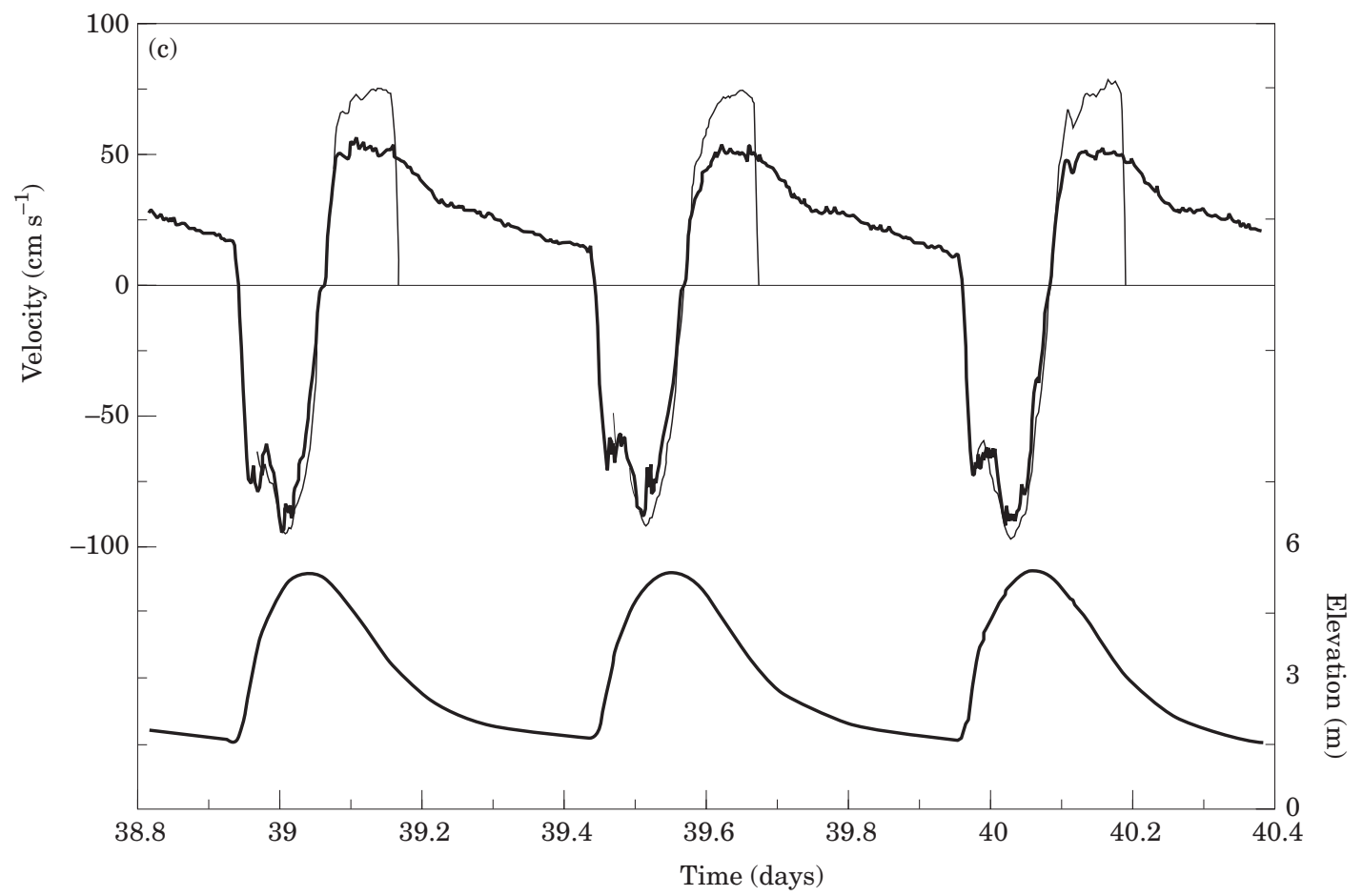

Figure 5. (c).

FIGURE 5. Time series from the lower current meter for 9 days of observations from 31 January to 10 February 1996 (days 31-42). (a) Axial velocity ( $\mathrm{cm} \mathrm{s}^{-1}$; upper curve) and surface elevation ( $\mathrm{m}$; lower curve). (b) Salinity (upper) and temperature $\left({ }^{\circ} \mathrm{C}\right.$; lower curve). (c) Expanded plot over three tidal cycles of elevation and velocity data including measurements from the upper current meter (thin line). Data for the upper current meter is limited to the periods when the instrument is immersed. Note the contrast between the flood (negative velocities) when there is minimal vertical shear and the ebb when velocity differences between the two current meters exceed $25 \mathrm{~cm} \mathrm{~s}^{-1}$ at times. Salinity and velocity data records were terminated by fouling of the instruments during the flood conditions on day 41 .

$u_{\star}^{2}=(\tau / \rho)$ and the local depth $h(y)$ or in terms of the mean velocity averaged over the section $u_{A}$ and the section mean depth $h_{A}$, i.e.

$$
P G=-g \frac{\partial \eta}{\partial x}=\frac{u_{\star}(y)^{2}}{h(y)}=\frac{u_{A}^{2}}{\Gamma^{2} h_{A}}
$$

where $\eta$ is the surface elevation. This balance defines the Chezy coefficient $\Gamma$ which is calculated from depth profile $h(y)$ of the section and the bottom roughness $z_{0}$ according to:

$$
\Gamma=\frac{\frac{1}{b} \int_{0}^{b} h^{3 / 2} \ln \left(h / z_{0}\right) d y}{\kappa h_{A}^{3 / 2}}
$$

where $b$ is the breadth of the estuary and $\kappa$ is von Karman's constant.

The sectional mean velocity is then found from the velocity measured by the current meter $u(y, z)$ as

$$
u_{A}=\Gamma\left(\frac{h_{A}}{h}\right)^{1 / 2} u_{\star}=\Gamma\left(\frac{h_{A}}{h}\right)^{1 / 2} \frac{\kappa u(y, z)}{\ln \left(z / z_{0}\right)}
$$

In a homogeneous flow without horizontal density gradients, this model would lead to frictionally induced velocity shears which would be equal and opposite on ebb and flood. From the observations [see Figure 5(c)], it is clear that the density driven flow induces an opposing shear which effectively neutralises the shear on the flood and enhances it on the ebb. To correct for this shear effect, we have included in our estimates of the total transport $Q$ a first order correction based on an estimate of the mean shear. With this term included the total transport across the section is written as

$$
Q=A\left(u_{A}+\frac{\beta \eta_{2}}{2}\right)
$$

where $\eta_{2}$ is the water height above the lower current meter and $\beta=0.05 \mathrm{~s}^{-1}$ is the estimate of the mean 


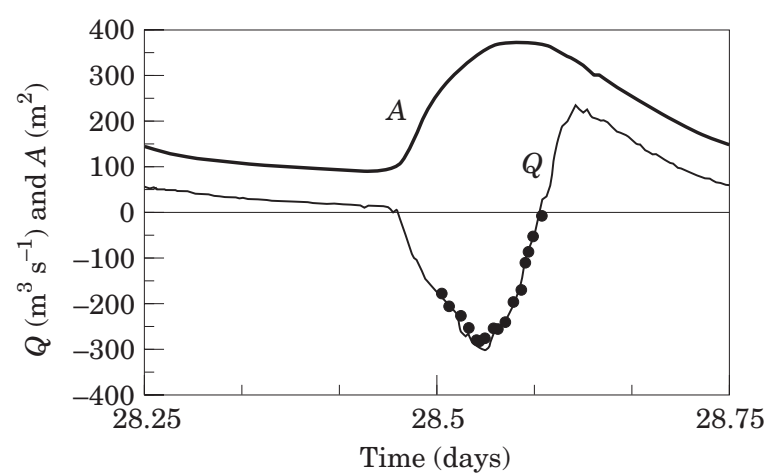

FIgURE 6. Comparison of transport $Q$ determined from the frictional model (continuous line) and directly observed transport (ellipses) from a roving boat-mounted ADCP making regular traverses of the channel on the seaward side of the bridge. Observations were made on 28 January 1997. The upper curve represents the variation in the cross-sectional area $A\left(\mathrm{~m}^{2}\right)$ of the study section.

shear based on the velocity difference between the two current meters which are separated by $2 \mathrm{~m}$ in the vertical (see Figure 4 for instrument positions). The observed value of the mean shear $\beta$ is of the same order as the shear deduced from the Hansen-Rattray model of the density driven flow using the observed longitudinal density gradient.

The cross-sectional area $A$, which varies with elevation $\eta$, is obtained from a trapezoidal model according to:

$$
\begin{gathered}
b=b_{0}+\eta\left(\cot \Theta_{1}+\cot \Theta_{2}\right) \\
A=A_{0}+\eta\left(b+b_{0}\right) / 2
\end{gathered}
$$

where $b=$ channel breadth, $A_{0}=$ area below the elevation datum level where $b=b_{0}$ and $\Theta_{1}$ and $\Theta_{2}$ are the slopes of the banks (see Figure 4 for schematic showing these parameters).

We have compared $Q$ based on Equations 6-8 with independent estimates of the cross-section transport from a roving boat-mounted ADCP (RDI $1.2 \mathrm{MHz}$ ) making regular traverses across the channel. The results (Figure 6) indicate satisfactory agreement on both the magnitude and timing of the flood flow with rms differences of $\approx 12 \mathrm{~m}^{3} \mathrm{~s}^{-1}$ between the two estimates of the flow which had a peak magnitude of $\approx 300 \mathrm{~m}^{3} \mathrm{~s}^{-1}$.

\section{The covariance of $Q_{t}$ and $S_{t}$ and a trial salt balance}

The time series of $Q$ determined from our frictional model for the full observation period is shown in Figure 7 as plots of the tidally-averaged component
$Q_{0}$ and the oscillatory component $Q_{t} . Q_{0}$ is generally positive (i.e. downstream) with magnitudes varying in the range $0-15 \mathrm{~m}^{3} \mathrm{~s}^{-1}$ and a mean over 16 tidal cycles (days 32-40) of $7 \cdot 6 \mathrm{~m}^{3} \mathrm{~s}^{-1} . Q_{t}$ exhibits upstream peak values of over $-400 \mathrm{~m}^{3} \mathrm{~s}^{-1}$ during the brief flood flow with rather smaller flows (peak $\approx 300 \mathrm{~m}^{3} \mathrm{~s}^{-1}$ ) on the ebb.

To construct the covariance term $\overline{Q_{t} S_{t}}$, we need to derive an estimate of the section-mean varying salinity from our observations which are continuous at one point only. In view of the high level of mixing and consequent lack of vertical structure we might, as a first approximation, assume that section average $S_{t}$ can be represented by a single point measurement. However, observations of the salinity variation at five stations across the section over a tidal cycle (Figure 8) reveal that the single point data introduces a bias. For most of the ebb flow, the difference between a point measurement $S_{\mathrm{rcm}}$ ( $1 \mathrm{~m}$ above the bed in midchannel) and the section mean $S_{a}$ is small but on the flood there are significant transverse gradients which would result in overestimate of the section mean. The transverse gradients involved are those which drive the transverse circulation which results in the axial convergence previously reported for the Conwy (Nunes \& Simpson, 1987). The lateral differences in salinity arise from an interaction between the transverse shear in the flow and the longitudinal salinity gradient. To a first approximation, the transverse gradients are proportional to the rate of salinity change and we have made a small correction using the observed $\frac{\partial S}{\partial t}$ and a fit to the data of Figure 8. The correction is written in the form:

$$
S_{a}=S_{r c m}+\gamma \frac{\partial S}{\partial t}+\delta
$$

where $\gamma=141 \mathrm{~s}^{-1}$ and $\delta=0 \cdot 17$. The resulting corrected salinity is shown in Figure 7 as the fluctuating $S_{t}$ along with the tidally averaged $S_{0}$ which is seen to increase from $\approx 5$ to $\approx 12.5$ over the first half of the record with little change thereafter.

We next form the product of $Q_{t}$ and $S_{t}$ and average it to yield an estimate of the covariance $\overline{Q_{t} S_{t}}$ which, when multiplied by $\rho$, is the upstream salt flux $S_{2}$. Numerically $S_{2}$ is almost equal to the covariance since

$$
S_{2}=\frac{\rho\left(\overline{Q_{t} S_{t}}\right)}{1000} \approx \frac{1025}{1000}\left(Q_{t} S_{t}\right)
$$

where we have substituted a mean value of the density $\rho=1025 \mathrm{~kg} \mathrm{~m}^{-3}$. We find that the mean covariance (Figure 9) is generally negative over the period of 


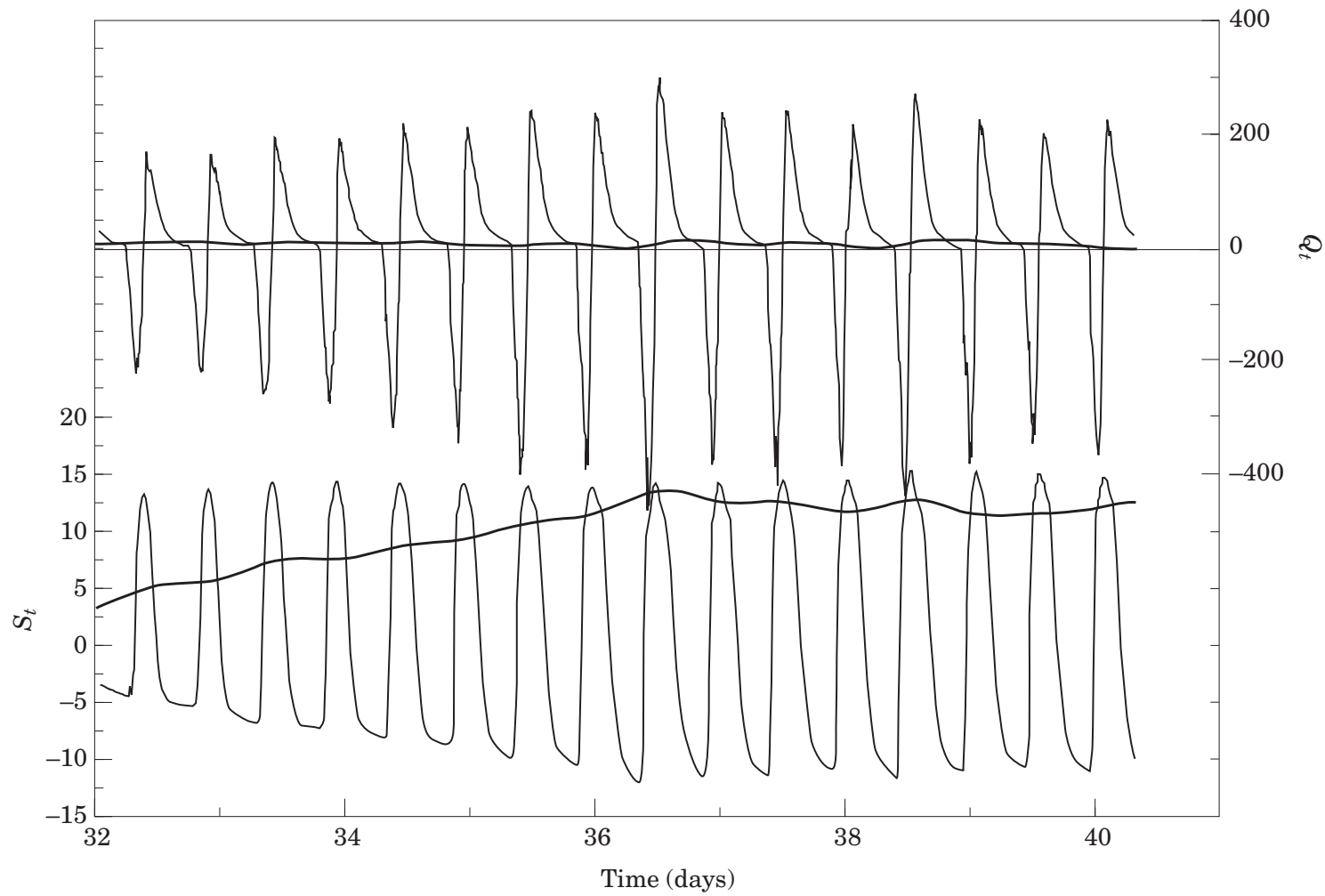

FIGURE 7. Transport and salinity. Upper plots: Tidally varying $Q_{t}$ (thin line) and mean $Q_{0}$ (thick line) in $\mathrm{m}^{3} \mathrm{~s}-1$. Lower plots: Tidally varying salinity $S_{t}$ (thin line) and mean $S_{0}$ (thick line). $Q_{0}$ and $S_{0}$ are based on $25 \mathrm{~h}$ averages.

observations indicating an upstream transport of salt. Averaged over 16 tidal cycles the mean upstream salt transport is $\approx 60 \mathrm{~kg} \mathrm{~s}^{-1}$. The corresponding downstream transport by the river flow $S_{1}$ is also shown in Figure 9 using estimates of daily mean discharge from the gauging station at Llanerch with a correction factor $(1.5)$ for the ungauged part of the catchment. The downstream transport is significantly less with a mean for the same period of $\approx 27 \mathrm{~kg} \mathrm{~s}^{-1}$ which would imply a net upstream transport of salt at Tal-y-Cafn of $\approx 33 \mathrm{~kg} \mathrm{~s}^{-1}$. A net gain in the total salt content of the estuary upstream of the bridge is also apparent from the observed increase in mean salinity at Tal-y-Cafn. At the end of the period the large increase in river discharge $\left(>100 \mathrm{~m}^{3} \mathrm{~s}^{-1}\right)$ reversed this net transport and rapidly reduced mean salinities to near zero by day 42 .

\section{Freshwater flux}

In an alternative approach, we may regard the freshwater input from the river as a passive tracer whose concentration is represented by the freshwater fraction $f$ which is defined as

$$
f=\frac{\sigma-S}{\sigma}
$$

where $\sigma$ is the salinity of seawater at the estuary mouth. The mean and fluctuating components of $f$ averaged over the cross section are just:

$$
\begin{gathered}
f_{0}=1-S_{0} / \sigma \\
f_{t}=f-f_{0}=\frac{1}{\sigma}\left(S_{0}-S\right)=-\frac{S_{t}}{\sigma}
\end{gathered}
$$

In terms of these quantities, the seaward flux of freshwater is then:

$$
\begin{aligned}
F W & =Q_{0} f_{0}+\overline{Q_{t} f_{t}} \\
& =Q_{0}\left(1-S_{0} / \sigma\right)-\frac{1}{\sigma} \overline{Q_{t} S_{t}}
\end{aligned}
$$

In a steady state salt balance we would have $F W=Q_{0}$ so that the freshwater discharge $Q_{f}$ may be found from

$$
Q_{f}=F W=\frac{-\overline{Q_{t} S_{t}}}{S_{0}}
$$



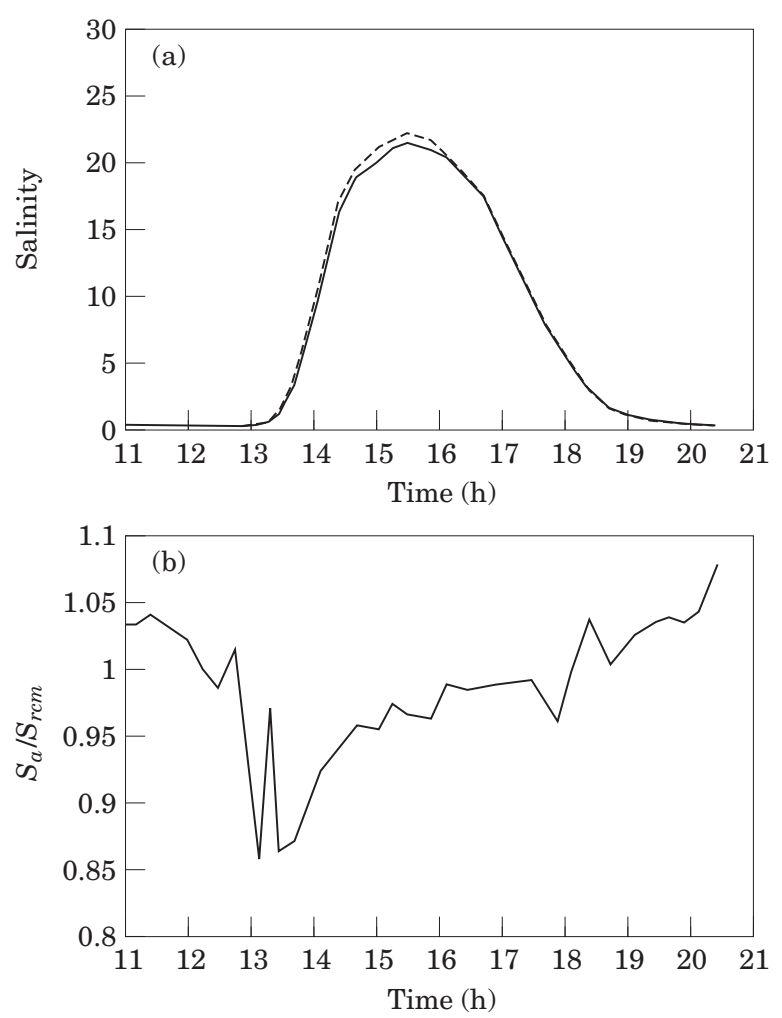

FIGURE 8. The relation between the section-averaged salinity $\left(S_{a}\right)$ and the value recorded by a single current meter $\left(S_{\text {rcm }}\right) 1 \mathrm{~m}$ above the bed in mid-channel on 14 July 1998. The section averaged salinity is based on repeated vertical profile data from five fixed stations across the estuary at a position $250 \mathrm{~m}$ north-east of Tal-y-Cafn Bridge. (a) $S_{a}$ and $S_{r c m}$ versus time in BST. Solid line: $S_{a}$; dashed line: $S_{r c m}$. (b) the ratio $S_{a} / S_{r c m}$

as proposed in Simpson et al. (1997). If we assume this balance to apply during days $32-40$, we obtain the estimates shown in Figure 10 in which $Q_{f}$ is overestimated by a factor of order 2-3. In part this is due to the assumption of a steady state which, in view of the rise in mean salinity is not applicable. We can avoid this weakness by using Equation 12 but, in order to do this, we need an estimate of the mean volume flux $Q_{0}$ which may be taken either from the average value of the total transport $Q$ as derived from our observations or from the net volume input as measured by river gauging. Using the observed mean transport $\left(Q_{0}=7.6 \mathrm{~m}^{3} \mathrm{~s}^{-1}\right)$ we find that the estimates of the freshwater flux from the upper estuary $F W$ are still too large. Setting the volume input $Q_{0}$ equal to the gauged input $Q_{f}$, our estimate of the mean downstream flux is then $F W \approx 4 \mathrm{~m}^{3} \mathrm{~s}^{-1}$ which is close to but still somewhat larger than the recorded flow. We would, however, expect $F W$ to exceed $Q_{f}$ at times when, as in the present case, the salinity is increasing in the upper estuary.

\section{Discussion and conclusion}

Our results indicate the form of the first order salt balance in the estuary but also highlight the difficulties in making convincing quantitative estimates of fluxes even in systems with relatively simple topography. Using the frictional flow model and only limited observational data on the estuary section, we have constructed the mean covariance of $Q_{t}$ and $S_{t}$. This quantity was generally negative over the whole period of the observations indicating a consistently upstream transport by the tidal diffusion term $S_{2}$. This upstream flux of salt exceeded the downstream movement of salt $S_{1}$ due to the freshwater input so that salt was accumulating in the upper part of the estuary, at least until day 40 when a flood flow commenced and flushed salt from the upper estuary. This pattern, of a relatively steady period of upstream movement of salt followed by swift downstream movement during flood periods, is probably typical for the Conwy which has highly variable flow responding rapidly to rainfall in the Snowdonia mountains. The estuary is probably not, therefore, generally in a steady state and useful application of Equation 13 to determine $Q_{f}$, if it were not known from river gauging, would be restricted to long term averages.

While they indicate the general form of the salt balance, the results do not constitute a full resolution of the salt budget under the low flow conditions observed for most of the period. The net upstream transport $\left(\mathbf{S}_{\mathbf{2}}-\mathbf{S}_{\mathbf{1}}\right)$ exceeds, by a factor of 2 , an upper-bound estimate of the rate of salt accumulation based on the volume storage upstream of the observation site and the observed salinity increase. This is not surprising in view of the sensitivity of the covariance term to the assumptions made in the detail of our calculations. For example omitting the shear correction term (Equation 7) leads to a large overestimate of $S_{2}$ as does the neglect of the transverse gradients of salinity.

The results do, however, confirm the key role of the covariance term in inducing upstream transport in the estuary and have helped to illuminate the way in which the net transport is brought about in a tidally oscillating flow. In a standing wave tidal regime, to which the Conwy system approximates, the horizontal velocity and the salinity tend to be in quadrature as the salinity variation at a point is driven primarily by tidal advection of the horizontal gradients. Without mixing, the tidal cycle would be an elastic reversible process with zero covariance and no net transport. In practice, mixing in the upper estuary tends to reduce the salinity of parcels of water advected upstream on the flood so that they are slightly fresher on their 


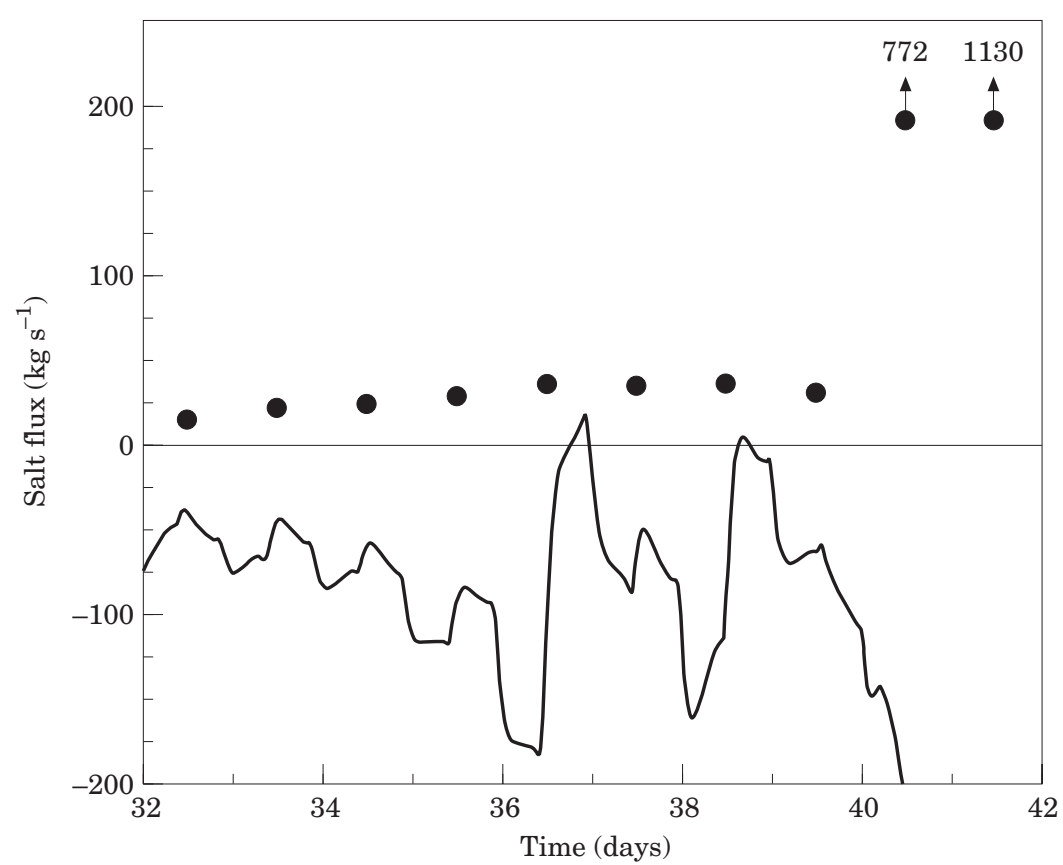

FIGURE 9. Salt flux components. The covariance (tidal pumping) term mean $\mathbf{S}_{2}=\rho \overline{Q_{t} S_{t}}\left(\mathrm{~kg} \mathrm{~s}{ }^{-1}\right.$; continuous curve); the daily averaged downstream transport $\mathbf{S}_{1}=\rho Q_{0} S_{0}$ ( $\mathrm{kg} \mathrm{s}^{-1}$; circles). Extreme values of $\mathbf{S}_{1}$ on days $40-42$ are associated with flood discharge from the Conwy.

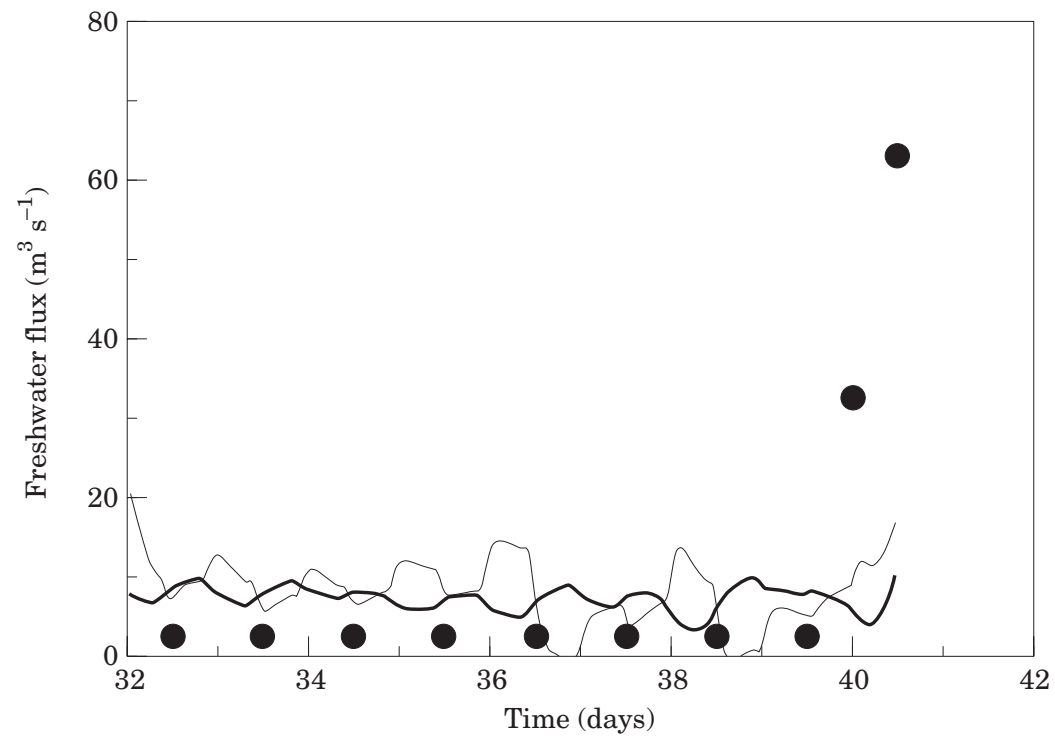

Figure 10. Net freshwater flux $\left(\mathrm{m}^{3} \mathrm{~s}^{-1}\right)$. (i) $F W$ from Equation 13 (thick line). (ii) Daily averaged $Q_{f}$ from river gauging ellipses). (iii) $Q_{f}$ estimated from Equation 14 which assumes a steady state salt balance (thin line).

return downstream. This flood-ebb asymmetry is illustrated in Figure 11 in which the tidally varying salinity $S_{t}$ is plotted against the integral of the tidal transport $Q_{t}$ which represents the volume of water which has moved past the bridge and into the upper estuary. It is clear from this plot that parcels of water generally have a slightly lower salinity on the ebb than on the flood and it is this difference, due to mixing in the upper estuary, which accounts for the residual flux.

The uncertainties in the salt balance are also reflected in our estimates of the freshwater flux which 


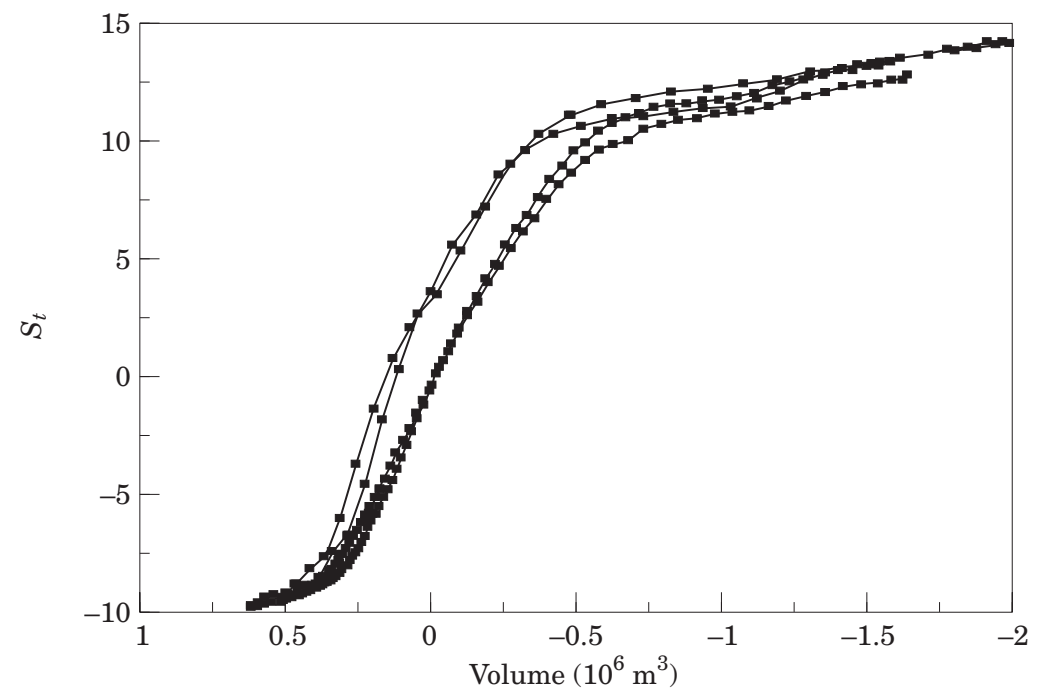

FIGURE 11. Plot for two tidal cycles of the tidally varying salinity $S_{t}$ versus volume of water in the estuary (in units of $10^{6} \mathrm{~m}^{3}$ ) above Tal-y-Cafn Bridge. Note that salinities are significantly higher during the rapid flood phase (data points well separated) than during the corresponding ebb (data points close together).

we may regard as a proxy for any dissolved constituent originating in the river system. In using Equation 10 to estimate constituent fluxes, we have to recognise the sensitivity to the estimate of $Q_{0}$ a quantity which is difficult to estimate directly from transport observations in estuaries like the Conwy where the ratio of mean to r.m.s. transport is low. If reliable river gauging is available to determine the volume transport, the application of Equation 12 should lead to better flux estimates providing that the constituent concentration and flow can be adequately sampled in time and across the estuary section to provide good estimates of the covariance of transport and constituent.

\section{Acknowledgements}

We are grateful to Dave Boon and Alan Nield for the design and implementation of the current meter deployment system and assistance with the observations. Our interest in the flux problem has been stimulated by discussions with J. E. Ong and W. K. Gong of CEMACS Universiti Sains Malaysia, Penang.

\section{References}

Dyer, K. R. 1997 Estuaries a Physical Introduction (2nd edition). John Wiley, New York, 195 pp.

Hansen, D. V. 1965 Currents and mixing in the Columbia River estuary. In Transactions of foint Conference on Ocean Science and Ocean Engineering. Marine Technical Society and American Society of Limnology and Oceanography, Washington D.C., pp. 943-955.

Hansen, D. V. \& Rattray, M. Jr. 1965 Gravitational circulation in straits and estuaries. Fournal of Marine Research 23, 104-122.

Hansen, D. V. \& Rattray, M. Jr. 1966 New dimensions in estuary classification. Limnology and Oceanography 11, 319-326.

Lane, A., Prandle, D., Harrison, A. J., Jones, P. D. \& Jarvis, C. J. 1997 Measuring fluxes in tidal estuaries: Sensitivity to instrumentation and associated data analyses. Estuarine, Coastal and Shelf Science 45, 433-451.

Nunes, R. A. \& Simpson, J. H. 1985 Axial convergence in a well-mixed estuary. Estuarine, Coastal and Shelf Science 20, 637-649.

Simpson, J. H., Gong, W. K. \& Ong, J. E. 1997 The determination of net fluxes from a mangrove estuary system. Estuaries 20, 103-109.

Smith, R. 1980 Buoyancy effects upon longitudinal dispersion in wide well-mixed estuaries. Proceedings of the Royal Society London A296, 467-496.

Turrell, W. R., Brown, J. \& Simpson, J. H. 1996 Salt intrusion and secondary flow in a shallow, well-mixed estuary. Estuarine, Coastal and Shelf Science 42, 153-169. 